\title{
Research on the Anti-wear Performance of Lubricants Based on the Stepwise Regression Method
}

\author{
Dongling XIAO ${ }^{1, a}$, Jianying $\mathrm{DA}^{\mathrm{l}, \mathrm{b}}$ \\ 1Automotive Department, Henan Vocational and Technical College of Communications, \\ Zhengzhou, 450005, China \\ 2 Automotive Department, Henan Vocational and Technical College of Communications, \\ Zhengzhou, 450005, China \\ adonglingxiao0120@163.com, bdjy1268@163.com
}

Keywords: Lubricants, Additives, Extreme pressure and anti-wear performance, Uniform Design

\begin{abstract}
Lubricating properties of the lubricant is generally evaluated by the friction and wear testing machine. In this paper, by using Four-ball test machine to measure the maximum non-card bite load value (PB), wear scar diameter (WSD) and Pd1.0, Pd2.0 value. The uniform design of experiments is firstly used for arranging multi-level and multi-factor experiments. The stepwise technique is adopted to put forward the regression equation. The compatibility of Nano-ceramic and T106 both additives is studied by a series of tests to improve the efficiency of use of lubricants.
\end{abstract}

\section{Introduction}

In order to make automotive engine oil achieve the desired results, there are some additives that include detergents, dispersants, anti corrosion agents, oiliness agents, antioxidants, viscosity index improvers, pour point depressants and anti-foam agent. There have extremely complex interactions between these additives. Between different additives not only produce the synergistic effect but also generated confrontation. Take advantage of synergies effect between these additives, it is one of the most reasonable and effective way about getting economic lubricant formulations, and it has also been a focus of research.

\section{Anti-wear performance research methods on Lubricants}

\subsection{The Basic Principle of Uniform Design}

All test design method essentially is selecting representative point in the range of test .Should follow "uniformly dispersed, neat comparable" principle when we selected represent the points, and the main point is to make the test data point have representative and easily study. The basic idea of the uniform design is only considered experimental points uniformly dispersed in the test range, so as to achieve the purpose of reducing the number of tests.

Design of $U_{n}\left(n^{m}\right)$ has $\mathrm{n}$ rows and $\mathrm{m}$ columns, the table that is generated by its vector $\mathrm{w}=\left(\mathrm{w}^{1}, \mathrm{w}^{2}, \mathrm{w}^{3} \ldots, \mathrm{w}^{\mathrm{m}}\right)$ is uniquely determined, we choose the best $\mathrm{S}$ column. it is uniformly transformed $\{1,2, \ldots . ., \mathrm{n}\}$ to $(0,1)$ by using Linear, and $U_{n}\left(n^{m}\right)$ is represented by $h^{k i}$ elements, then converted into:

$$
\begin{aligned}
x^{k i} & =\frac{2 h_{k i}-1}{2 n}, i=1,2, \cdots \cdots, m, k=1,2, \cdots \cdots, n \\
x^{k} & =\left(x^{k 1}, x^{k 2}, \cdots \cdots, x^{k n}\right), k=1,2, \cdots \cdots, n
\end{aligned}
$$

Thus, $\mathrm{n}$ test points are converted into $\mathrm{n}$ points among of $[0,1]^{\mathrm{m}}=\mathrm{Q}^{\mathrm{m}}, \mathrm{n}$ points are $x^{1}, x^{2} \cdots \cdots x^{n}$. Considering of uniformity of the original $\mathrm{n}$ test points, it is equivalent to assess uniformity of the $x^{1}, x^{2} \cdots \cdots x^{n}$ in the $\mathrm{Q}^{\mathrm{m}}$. There are many criterion of measuring uniformity, but deviation criteria are widely accepted. Mathematical models are as follows: 


$$
D\left(x^{1}, x^{2} \cdots \cdots x^{n}\right)=\sup _{x \in Q^{m}}\left|\frac{n_{x}}{n}-v(x)\right|
$$

Calculating deviation of the point set $\left\{x^{1}, x^{2} \cdots \cdots x^{n}\right\}$ in $\mathrm{Q}^{\mathrm{m}}$ by using the formula, and then getting the smallest group, this corresponding $\mathrm{S}$ column $\left(\mathrm{s}^{\mathrm{m}}\right)$ is optimal protocol.

There have a using table in each uniform design table, which indicates how we use the appropriate column from the design table, and the uniformity of the test program.

Uniform design has its own unique way of distribution, mainly as follows:

First, each level of each factor did once and only once the test.

Second, any two test point lay on the plane of the grid points, each row and each column has only one test point.

Third, pilot programs consisting of any two column in Uniform design table are general not equivalent .This nature is very different between Uniform design table and orthogonal uniform design table , so each uniform design table each table must have a additional usage table.

Last, when the number of levels factors is increasing, the amount of the increase of the number of trials is equal to amount of increase of the number of levels. Because of this feature, so that uniform design is easily used.

\subsection{The Basic Principle of Stepwise Regression}

Stepwise regression method is method of processing data. that is "optimal" regression equation. This method does not need to calculate the partial correlation coefficient, and calculated process relatively simple, because each step have to be exam, thus ensuring all factors of the final agenda obtained are significant.

Because of the interaction between the variables, and multiple linear regression model is not sufficient to reflect the actual situation. So it is often using quadratic regression model.

\subsubsection{Mathematical model expressed}

Assuming there are $\mathrm{m}$ Factors, $x_{1}, \cdots \cdots, x_{m}$, quadratic regression model is as following

$$
Y=\alpha_{0}+\sum_{i=1}^{m} a_{i} x_{i}+\sum_{i=1}^{m} a_{i i} x_{i}^{2}+\sum_{i=1}^{m} a_{i j} x_{i} x_{j}+\varepsilon
$$

Its expansion is:

$$
Y=\beta_{0}+\beta_{1} X_{1}+\beta_{2} x_{2}+\beta_{3} x_{1}^{2}+\beta_{4} X_{1} X_{2}+\beta_{5} x_{2}^{2}+\cdots \cdots+\varepsilon
$$

Assuming $X_{1}=x_{1}, X_{2}=x_{2}, X_{3}=x_{1}^{2}, X_{4}=x_{1} x_{2}, X_{5}=x_{2}^{2}, \ldots$, then the above equation can be transformed into a mathematical model of multiple linear regression.

$$
Y=\beta_{0}+\beta_{1} X_{1}+\beta_{2} X_{2}+\beta_{3} X_{3}+\cdots \cdots+\varepsilon
$$

In regression analysis, often make the argument number is $n-1$, and remember is $Y=X_{n}$, then the mathematical model is:

$$
X_{n}=\beta_{0}+\beta_{1} X_{1}+\beta_{2} X_{2}+\beta_{3} X_{3}+\cdots+\beta_{n-1} X_{n-1}+\varepsilon
$$

\subsubsection{Data Standardization}

Due to the different $X_{j}(j=1,2, \cdots, n)$, their ranges and units are not the same, so in order to be calculated under the influence of the non-dimensional, we have all the data regression often be a "standardized" transformation, and even if:

$$
Z_{j}=\frac{X_{j}-\bar{X}_{j}}{\sigma_{j}}, j=1,2, \cdots n
$$

Order: $\bar{X}_{j}=\frac{1}{n} \sum_{j=1}^{n} X_{j}, \quad \sigma_{j}^{2}=\frac{1}{n} \sum_{j=1}^{n}\left(X_{j}-\bar{X}_{j}\right)$,then the mathematical model is:

$$
Z_{n}=\beta^{\prime} Z_{1}+\beta_{2}^{\prime} Z_{2}+\cdots+\beta_{n-1}^{\prime} Z_{n-1}+\varepsilon
$$

\subsubsection{The regression equation}


Set by the model (9) obtained regression equation:

$$
\hat{Z}_{n}=\hat{\beta}_{1}^{\prime} Z_{1}+\hat{\beta}_{2}^{\prime} Z_{2} \cdots+\hat{\beta}_{n-1}^{\prime} Z_{n-1}
$$

That is:

$$
\hat{X}_{n}=\left(\bar{X}_{n}-\frac{\sigma_{n}}{\sigma_{1}} \hat{\beta}_{1}^{\prime} \bar{X}_{1}-\frac{\sigma_{n}}{\sigma_{2}} \hat{\beta}_{2}^{\prime} \bar{X}_{2}-\cdots-\frac{\sigma_{n}}{\sigma_{1}} \hat{\beta}_{1}^{\prime} \bar{X}_{n-1}\right)+\frac{\sigma_{n}}{\sigma_{1}} \hat{\beta}_{1}^{\prime} X_{1}
$$

\section{Extreme Pressure and Anti-wear Performance Test of Lubricants}

In the testing ,this paper choose Nano-ceramic and T106 two additives as experimental factors, and uses the uniform design method, uniform design table is $U_{5}\left(5^{4}\right)$, In order to investigate interact effect on extreme pressure and anti-wear each factor, test results fit the data by use of quadratic polynomial regression model. Fitting equation is.

$$
Y=\beta_{0}+\beta_{1} x_{1}+\beta_{2} x_{2}+\beta_{3} x_{1}^{2}+\beta_{4} x_{1} x_{2}+\beta_{5} x_{2}^{2}
$$

We deal with test data by using SPSS software and stepwise method, and then obtained the regression model of $\mathrm{P}_{\mathrm{B}}$ value, $\mathrm{P}_{\mathrm{d} 1.0}$ value, $\mathrm{P}_{\mathrm{d} 2.0}$ values and $W S D_{30}^{392}$. $\mathrm{P}_{\mathrm{B}}$ value, $\mathrm{P}_{\mathrm{d} 1.0}$ value, $\mathrm{P}_{\mathrm{d} 2.0}$ values are used to assess the performance of extreme pressure lubrication, $W S D_{30}^{392}$ is used to assess the anti-wear properties of lubricants. The absolute value of standardized coefficients can be directly used to determine the independent variable on the dependent variable degree of influence. Sig is the significance level, and its value is closer to 0 , the more meaningful the regression equation; $t$ value indicates the importance of the factor, $t$ absolute value, the more large said that the more important factor; $\mathrm{R}$ is the correlation coefficient, the closer the absolute value of a linear correlation between the two variables more closely, the closer to 0 , the less dense linear correlation.

In the test, we add Nano-ceramic wear agents and detergents T106 into the base oil, and then obtain $\mathrm{P}_{\mathrm{B}}$ value, $\mathrm{P}_{\mathrm{d} 1.0}$ value, $\mathrm{P}_{\mathrm{d} 2.0}$ value and $W S D_{30}^{392}$ value, the test results shown in Table 1 .

Nano-ceramic and T106 compatibility test results Table 1

\begin{tabular}{|c|c|c|c|c|c|c|}
\hline Test No & $\begin{array}{c}\text { Nano- } \\
\text { solution } \\
\left(\mathrm{x}_{1}\right) / \%\end{array}$ & $\mathrm{~T} 106\left(\mathrm{x}_{2}\right) / \%$ & $\mathrm{P}_{\mathrm{B}} / \mathrm{N}$ & $\mathrm{P}_{\mathrm{d} 1.0} / \mathrm{N}$ & $\mathrm{P}_{\mathrm{d} 2.0} / \mathrm{N}$ & $W S D_{30}^{392} / \mathrm{mm}$ \\
\hline 1 & 2 & 2 & 1107.4 & 1107.4 & 1244.6 & 0.75 \\
\hline 2 & 2.5 & 4 & 1107.4 & 1107.4 & 1519 & 0.62 \\
\hline 3 & 3 & 1 & 1087.8 & 1087.8 & 1254.4 & 0.7 \\
\hline 4 & 3.5 & 3 & 1068.2 & 1078 & 1411.2 & 0.42 \\
\hline 5 & 4 & 5 & 1185.8 & 1283.8 & 1509.2 & 0.41 \\
\hline
\end{tabular}

\subsection{Regression of $\mathbf{P}_{\mathrm{B}}$ Values}

Selecting quadratic polynomial regression model and SPSS software, which screened the variables in order to obtain a fitting model of $\mathrm{P}_{\mathrm{B}}$ value, as follows:

$Y_{1}=393.589+424.270 x_{1}-73.440 x_{1}^{2}+13.133 x_{1} x$

Assuming: $\mathrm{R}=0.993$, $\mathrm{Sig}=0.000$,regression coefficients is as follow Table 2

$\mathrm{P}_{\mathrm{B}}$ value of regression coefficient table 2

\begin{tabular}{|c|c|c|c|c|c|}
\hline \multirow{2}{*}{ Model } & \multicolumn{2}{|c|}{$\begin{array}{c}\text { Unstandardized } \\
\text { Coefficients }\end{array}$} & $\begin{array}{c}\text { Standardize } \\
\mathrm{d} \\
\text { Coefficient } \\
\mathrm{s}\end{array}$ & $\mathrm{t}$ & Sig \\
\cline { 2 - 5 } & $\mathrm{B}$ & Std. & Beta & & \\
\hline
\end{tabular}




\begin{tabular}{|c|c|c|c|c|c|}
\hline \multicolumn{1}{|c|}{ (Constant) } & 393.589 & 19.590 & & 20.092 & 0.000 \\
\hline Nano-solution $\left(x_{1}\right)$ & 424.270 & 27.162 & 2.091 & 15.620 & 0.000 \\
\hline $\begin{array}{l}\text { Nano-square solution } \\
\left(\begin{array}{c}x_{1}^{2} \\
\text { N }\end{array}\right.\end{array}$ & -73.440 & 7.486 & -1.343 & -9.807 & 0.000 \\
\hline $\begin{array}{c}\text { Nano- } \\
\text { solution*T106 }\left(x_{1} \times x_{2}\right)\end{array}$ & 13.133 & 2.347 & 0.239 & 5.603 & 0.000 \\
\hline
\end{tabular}

Among Table 2, Standardized Coefficients, 2.091,is positive, so first order effects of Nanoceramic anti-wear agent can increase the value of lubricants $\mathrm{P}_{\mathrm{B}}$, but Standardized Coefficients, 1.343 ,is negative so the second-order effects will reduce $P B$ value. Thus, adding a small amount of Nano-ceramic anti-wear agents can increase the value of lubricants $\mathrm{P}_{\mathrm{B}}$. Standardized Coefficients, 0.239 ,but the role of the smallest among the three ,so Second-order interaction between Nanoceramic and detergent T106 will have a positive value for $\mathrm{P}_{\mathrm{B}}$ synergies.

\subsection{Regression of $\mathbf{P d}_{1.0}$ Values}

Selecting quadratic polynomial regression model and SPSS software, which screened the variables in order to obtain a fitting model of Pd1.0value, as follows:

$$
Y_{2}=511.151+326.921 x_{1}-55.507 x_{1}^{2}+16.272 x_{1} x_{2}
$$

Assuming: $\mathrm{R}=0.990$, Sig $=0.000$, regression coefficients is as follow Table 3

\begin{tabular}{|c|c|c|c|c|c|}
\hline \multirow[t]{2}{*}{ Model } & \multicolumn{2}{|c|}{$\begin{array}{l}\text { Unstandardized } \\
\text { Coefficients }\end{array}$} & \multirow{2}{*}{$\begin{array}{c}\begin{array}{c}\text { Standardized } \\
\text { Coefficients }\end{array} \\
\text { Beta } \\
\end{array}$} & \multirow[t]{2}{*}{$\mathrm{t}$} & \multirow[t]{2}{*}{ Sig } \\
\hline & $\mathrm{B}$ & Std. Error & & & \\
\hline (Constant) & 511.151 & 19.781 & & 25.836 & 0.000 \\
\hline Nano-solution $\left(X_{1}\right)$ & 326.921 & 27.429 & 1.876 & 11.915 & 0.000 \\
\hline Nano-square solution $\left(x_{1}^{2}\right)$ & -55.507 & 7.560 & -1.182 & -7.339 & 0.000 \\
\hline $\begin{array}{c}\text { Nano- } \\
\text { solution*T106 }\left(x_{1} \times x_{2}\right)\end{array}$ & 16.272 & 2.367 & 0.347 & 6.872 & 0.000 \\
\hline
\end{tabular}

Among Table 3, Standardized Coefficients, 1.876, is positive, first order effects of Nano-ceramic anti-wear agent can increase the value of lubricants $P_{\mathrm{d} 1.0}$. Standardized Coefficients, -1.182, is negative, so the second-order effects will reduce $\mathrm{P}_{\mathrm{d} 1.0}$ value. Thus, adding a small amount of Nanoceramic anti-wear agents can increase the value of lubricants $\mathrm{P}_{\mathrm{d} 1.0}$. Standardized Coefficients, 0.347,is positive, but the role of the smallest among the three ,so Second-order interaction between Nano-ceramic and detergent T106 will have a positive value for $\mathrm{P}_{\mathrm{d} 1.0}$ synergies.

\subsection{Regression of $\mathbf{P}_{\mathbf{d} 2.0}$ Values}

Selecting quadratic polynomial regression model and SPSS software, which screened the variables in order to obtain a fitting model of $\mathrm{P}_{\mathrm{d} 2.0 \text { value, as follows: }}$

$$
Y_{3}=577.581+354.142 x_{1}-61.439 x_{1}^{2}+30.418 x_{1} x_{2}
$$

Assuming: $\mathrm{R}=0.975$, Sig $=0.000$, regression coefficients is as follow Table 4 Pd2.0value of regression coefficient table 4

\begin{tabular}{|c|c|c|c|c|c|}
\hline \multirow{2}{*}{ Model } & \multicolumn{2}{|c|}{$\begin{array}{c}\text { Unstandardized } \\
\text { Coefficients }\end{array}$} & $\begin{array}{c}\text { Standardized } \\
\text { Coefficients }\end{array}$ & \multirow{2}{*}{ t } & Sig \\
\cline { 2 - 4 } & $\mathrm{B}$ & $\begin{array}{c}\text { Std. } \\
\text { Error }\end{array}$ & Beta & \\
\hline
\end{tabular}




\begin{tabular}{|c|c|c|c|c|c|}
\hline (Constant) & 577.581 & 39.372 & & 14.661 & 0.000 \\
\hline Nano-solution( $\left.{ }^{x_{1}}\right)$ & 354.142 & 54.610 & 1.591 & 6.484 & 0.000 \\
\hline Nano-square solution $\left({ }^{x_{1}^{2}}\right)$ & 61.439 & 15.049 & -1.024 & -4.081 & 0.002 \\
\hline $\begin{array}{c}\text { Nano- } \\
\text { solution*T106 }\left(x_{1} \times x_{2}\right)\end{array}$ & 30.418 & 4.711 & 0.507 & 6.449 & 0.000 \\
\hline
\end{tabular}

Among Table 4, Standardized Coefficients, 1.591, is positive, first order effects of Nano-ceramic anti-wear agent can increase the value of lubricants $\mathrm{P}_{\mathrm{d} 2.0}$.Standardized Coefficients, -1.024 , is negative, but the second-order effects will reduce $\mathrm{P}_{\mathrm{d} 2.0}$ value. Thus, adding a small amount of Nanoceramic anti-wear agents can increase the value of lubricants $\mathrm{P}_{\mathrm{d} 2.0}$. Standardized Coefficients, 0.507 ,is positive, but the role of the smallest among the three ,so Second-order interaction between Nano-ceramic and detergent T106 will have a positive value for $\mathrm{PP}_{\mathrm{d} 2.0}$ synergies.

\section{Regression of $W S D_{30}^{392}$ Values}

Selecting quadratic polynomial regression model and SPSS software, which screened the variables in order to obtain a fitting model of $W S D_{30}^{392}$ value, as follows:

$$
Y_{3}=1.012-0.136 x_{1}+0.0023 x_{1}^{2}-0.0024 x_{1} x_{2}
$$

Assuming: $\mathrm{R}=0.969$, Sig $=0.000$, regression coefficients is as follow Table 5

$$
W S D_{30}^{392} \text { value of regression coefficient table } 5
$$

\begin{tabular}{|c|c|c|c|c|c|}
\hline \multirow{2}{*}{ Model } & \multicolumn{2}{|c|}{$\begin{array}{c}\text { Unstandardized } \\
\text { Coefficients }\end{array}$} & $\begin{array}{c}\text { Standardized } \\
\text { Coefficients }\end{array}$ & \multirow{2}{*}{$\mathrm{t}$} & \multirow{2}{*}{ Sig } \\
\cline { 2 - 5 } & $\mathrm{B}$ & $\begin{array}{c}\text { Std. } \\
\text { Error }\end{array}$ & Beta & & \\
\hline (Constant) & 1.012 & 0.024 & & 40.215 & 0.000 \\
\hline Nano-solution( $\left.{ }^{x_{1}}\right)$ & -0.136 & 0.034 & -1.068 & -3.926 & 0.002 \\
\hline $\begin{array}{l}\text { Nano-square solution } \\
\left(x_{1}^{2}\right)\end{array}$ & 0.0023 & 0.010 & 0.665 & 2.381 & 0.035 \\
\hline $\begin{array}{c}\text { solution*T106 }\left(X_{1} \times x_{2}\right) \\
\text { sano- }\end{array}$ & -0.0024 & 0.003 & -0.691 & -7.911 & 0.000 \\
\hline
\end{tabular}

Among Table 5, Standardized Coefficients, -1.068, is negative, first order effects of Nanoceramic anti-wear agent can reduce the $W_{S D_{30}^{392}}^{3}$ value, and increase abrasion resistance of lubricants. Standardized coefficients respectively were 0.664 and -0.692 , but the second-order effects will increase the $W S D_{30}^{392}$ value, and reduce abrasion resistance of lubricants. Second-order interaction between Nano-ceramic and detergent T106 will reduce the $W_{S D_{30}^{392}}$ value, and increase abrasion resistance of lubricants.

\section{Conclusion}

From the above values for $\mathrm{P}_{\mathrm{B}}, \mathrm{P}_{\mathrm{d} 1.0}$ value, $\mathrm{P}_{\mathrm{d} 2.0}$ value and $W S D_{30}^{392}$. The value of analysis showed that the interaction of Nano-ceramic wear agents and detergents T106 lubricant can improve abrasion resistance of lubricants.

\section{References}

[1] Wenxuan Huang.Lubricant additives Application Guide, China Petrochemical Press,2004. 
[2] Q.L.Yang.Nano-Ceramic Engine Oil and Energy Conservation of Automobile, Engineering Science and Technology.39 60(2011).

[3] Chunli Bai.Nano Science and Technology, Yunnan Science and Technology Press, Kunming,2004.

[4] Xiaoqun He.Regression analysis, China Renmin University Press,Beijing,2001.

[5] Kaitai Fang.Uniform design and uniform design table, Science Press,Beijing,2004.

[6] Yang wan, Qiaosheng Pu,Qunji Xue,Zhixing Su. Anti-wear and extreme pressure characteristics of 2-mercaptobenzothiazole derivative as the potential lubricating oil additive.Wear.1996,192:74 77P.

[8]Zhang Z.W.Liu,Q.Xue.Study on lubricationg mechanism of $\mathrm{La}(\mathrm{OH}) 3$ nanocluster modified by compound containing nitrogenin liquid paraffin,wear,1998,218(2),139-144.

[9]Wu Zhi-shen,Zhou Jing-fang,etal. Structure Characterization and Tribological Behavior of Surface-Modified Zro2 Nano-particles, Chemical Reaserach,2001,4(2):1008-1011.

[10]Jiping Ye,Makoto Kano and Yoshiteru Yasuda. Evaluation of local mechanical properties in depth in MoDTC/ZDDP and ZDDP tribocherniacl reacted Films Using Nano-indentation. Tribology Lerrers .2002(7):41-47.

[11] www.chinalubricant.com.

[12] www.Lubrizol.com. 